\title{
Heat Treatment of Buckypaper for Use in Volatile Organic Compounds Sampling
}

\author{
Jonghwa Oh, ${ }^{1}$ Evan L. Floyd, ${ }^{2}$ Mahesh Parit, ${ }^{3}$ Virginia A. Davis, ${ }^{3}$ and Claudiu T. Lungu ${ }^{1}$ \\ ${ }^{1}$ Environmental Health Sciences, University of Alabama at Birmingham, Birmingham, AL, USA \\ ${ }^{2}$ Occupational and Environmental Health, University of Oklahoma, Oklahoma City, OK, USA \\ ${ }^{3}$ Chemical Engineering, Auburn University, Auburn, AL, USA \\ Correspondence should be addressed to Claudiu T. Lungu; clungu@uab.edu
}

Received 2 June 2016; Revised 9 September 2016; Accepted 15 September 2016

Academic Editor: Zafar Iqbal

Copyright (C) 2016 Jonghwa Oh et al. This is an open access article distributed under the Creative Commons Attribution License, which permits unrestricted use, distribution, and reproduction in any medium, provided the original work is properly cited.

\begin{abstract}
Three types of buckypapers (BPs), two of them fabricated with arc discharge (AD) single-walled carbon nanotubes (SWNTs) (acetone-cleaned AD BP and methanol-cleaned AD BP) and one with high-pressure carbon monoxide (HiPco) SWNTs (HiPco $\mathrm{BP})$, were heat-treated at different conditions to find the specific conditions for each type that improve the adsorption properties. Based on thermogravimetric analysis (TGA) data, three heat treatment conditions were designed for the AD BPs and another three conditions for the HiPco BPs. Also, changes in weight and physical integrity before and after the heat treatment were considered. Heating at $300^{\circ} \mathrm{C}$ for 90 minutes was selected for acetone-cleaned AD BP, in which the BP kept its physical integrity and yielded a relatively high Brunauer, Emmett, and Teller (BET) surface area $\left(970 \pm 18 \mathrm{~m}^{2} / \mathrm{g}\right)$, while methanol-cleaned AD BP was excluded because of its physical change. For HiPco BP, a condition of $300^{\circ} \mathrm{C}$ heating for 30 minutes was chosen as a relatively higher surface area $\left(933 \pm 54 \mathrm{~m}^{2} / \mathrm{g}\right)$ and less weight loss $(5 \%)$ were observed.
\end{abstract}

\section{Introduction}

Strategies to fabricate CNT films or buckypaper (BP) have been developed mostly for use in electronic devices [1]. Processes such as vacuum filtration, solution spraying, drop casting, and layer by layer assembly have been widely investigated and successfully used $[1,2]$. Certain fabrication methods such as vacuum filtration or solution spraying commonly require suspending CNTs in surfactants for obtaining a homogenous solution and, after the deposition on a substrate like a membrane filter or glass, rinsing the deposited cake with purified water to remove the surfactants $[1,3,4]$. Surfactants could insulate CNTs and possibly lower their conductivity [5, 6]. Although it is often thought that the surfactants could be completely removed with water rinsing $[3,7]$, studies have found remaining surfactants in SWNT films [5-7]. Additional purification process of surfactants such as heat or acid treatments has been suggested [5-7].

In our previous study for the application of the photothermal desorption (PTD) [8], arc discharge (AD) and highpressure carbon monoxide (HiPco) single-walled carbon nanotubes (SWNTs) were fabricated into BPs through the vacuum filtration method, a relatively simple and inexpensive procedure $[1,6]$. We determined that the fabrication process left surfactant residues in AD BPs. Since AD SWNTs were presuspended in surfactants (i.e., sodium cholate and sodium dodecyl sulfate) when purchased, a cleaning process with DI water and solvent rinsing was involved; however, increased weight of the BP compared with theoretically predicted weight was observed even after the cleaning, which was attributed to the residual surfactants left within the fabricated AD BPs.

The purpose of this study was to find the appropriate heat treatment conditions for each type of BP in order to improve adsorption properties by removing surfactants or solvent related impurities. For AD BPs, our main purpose was to remove surfactants imbedded in $\mathrm{AD} B \mathrm{BP}$ rather than removing metal impurities, so heat treatment at a mild temperature was performed. Because of the low probability for SWNTs to be oxidized at mild temperatures $[6,9,10]$ and simplified furnace operation, heat treatment was performed in air environment. In addition, HiPco BPs were included in this study 
mainly to remove any impurities involved in the synthesis and fabrication process. Thermogravimetric analysis (TGA) was performed in advance to determine appropriate heat treatment conditions specific to each type of BPs.

\section{Materials and Methods}

2.1. Buckypaper (BP) Fabrication. The fabrication procedure was adopted from our previous study [8]. Arc discharge (AD) SWNT solution $(1 \mathrm{mg} / \mathrm{mL}, 94.5 \%$ pure, $1.2-1.7 \mathrm{~nm}$ in diameter, $0.1-4 \mu \mathrm{m}$ in length) presuspended in surfactants ( $1 \% \mathrm{w} / \mathrm{v}$ sodium cholate and sodium dodecyl sulfate in water) and HiPco SWNTs (85\% pure, $0.8-1.2 \mathrm{~nm}$ in diameter, 0.1$1 \mu \mathrm{m}$ in length) powder were purchased from Nanointegris Inc. (Quebec, Canada). A typical filtration and suspension procedure to fabricate BPs was employed and two fabrication/cleaning methods for AD BP (i.e., acetone-cleaned and methanol-cleaned) and one method for HiPco BP were used. For the fabrication of AD BPs, $50 \mathrm{~mL}(50 \mathrm{mg})$ of the AD SWNT solution was mixed with $400 \mathrm{~mL}$ of solvent (either acetone or methanol) for 15 hours. The suspension was then vacuum-filtered through a polytetrafluoroethylene (PTFE) membrane filter $(47 \mathrm{~mm}$ in diameter, $5 \mu \mathrm{m}$ pore, EMD Millipore, Darmstadt, Germany) and a series of two alternating rinses were used after the SWNT cake was deposited on the filter but not dried. The SWNT cake was first rinsed with $250 \mathrm{~mL}$ of deionized water $(18.2 \mathrm{M} \Omega \mathrm{cm})$ and then $50 \mathrm{~mL}$ of solvent to make either acetone-cleaned or methanol-cleaned AD BP. The deposited cake was allowed to dry for 30 minutes under vacuum plus another 2 hours without vacuum while on the membrane filter and a BP was obtained by delaminating the dried SWNT cake from the filter. For HiPco BP preparation, $50 \mathrm{mg}$ of powdered HiPco SWNTs was suspended in $400 \mathrm{~mL}$ methanol and ultrasonicated using a $490 \mathrm{~W}$ bath sonicator (BRANSON CPX5800H, Danbury, CT) for 150 minutes. The solution was vacuum-filtered through the same type of PTFE membrane filter and allowed to dry in the same way as mentioned before (30 minutes under vacuum plus another 2 hours without vacuum). The SWNT cake was then delaminated from the filter to obtain a BP.

2.2. Thermogravimetric Analysis (TGA). TGA (Q500, TA Instruments, New Castle, DE) was performed on the fabricated BPs. Two BPs of each fabrication method were used and results were averaged. The samples were held at $120^{\circ} \mathrm{C}$ for 20 minutes to remove residual moisture and heated to $800^{\circ} \mathrm{C}$ with a ramping rate of $10^{\circ} \mathrm{C} / \mathrm{min}$ in air environment, followed by 45 -minute hold. Based on the data obtained (see Results), further heat treatment conditions were determined. For the AD BPs, three conditions were set in which the surfactants were expected to be completely removed without a considerable weight loss compared with the theoretically predicted weight (i.e., $50 \mathrm{mg}$ ): $300^{\circ} \mathrm{C}$ for $90 \mathrm{~min}, 350^{\circ} \mathrm{C}$ for $60 \mathrm{~min}$, and $300^{\circ} \mathrm{C}$ for $120 \mathrm{~min}$. For the HiPco BPs, the treatment conditions were set where the surface area was expected to be increased with a minimal weight loss: $350^{\circ} \mathrm{C}$, $300^{\circ} \mathrm{C}$, and $250^{\circ} \mathrm{C}$ for $30 \mathrm{~min}$.

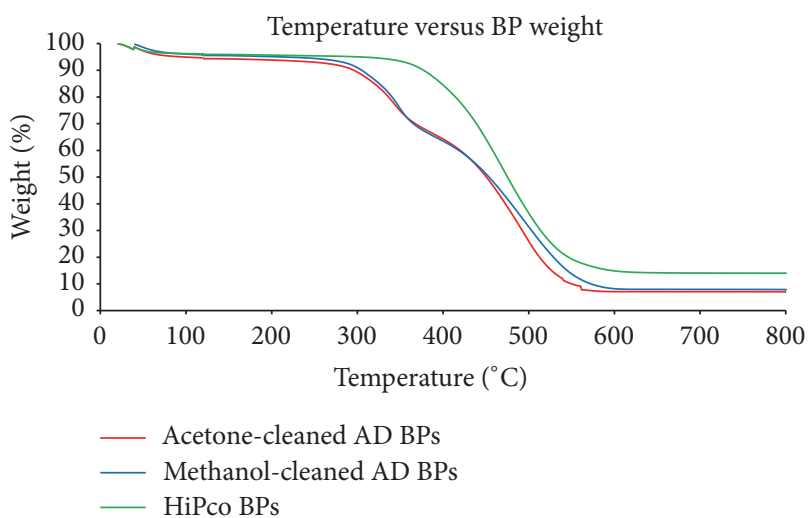

FIgURE 1: TGA results for acetone-cleaned AD BPs, methanolcleaned AD BPs, and HiPco BPs.

2.3. Heat Treatment. Heat treatment was performed with a muffle furnace (Thermolyne ${ }^{\mathrm{TM}}$ F48025-60-80, Thermo Fisher Scientific ${ }^{\mathrm{TM}}$, Waltham, MA). The ramping rate was $10^{\circ} \mathrm{C} / \mathrm{min}$ and samples were held for the designated conditions (time and temperature) and then cooled down to room temperature. Changes in weight and physical integrity (i.e., appearance and surface) were recorded before and after heat treatment.

2.4. Characterization of Adsorption Properties. Surface area and pore size were analyzed with a physisorption analyzer (Micromeritics ${ }^{\circledR}$ ASAP 2020, Norcross, GA) using $\mathrm{N}_{2}$ at $77 \mathrm{~K}$. Samples were degassed for an hour at a temperature in which each sample was heat-treated prior to the measurement. Analysis was duplicated for each BP and averaged. Brunauer, Emmett, and Teller (BET) theory was used to determine surface area and subsequently mean pore width.

\section{Results and Discussions}

3.1. TGA. $10 \%$ weight loss of acetone-cleaned AD, methanolcleaned AD BPs, and HiPco BPs occurred at an average of $295 \pm 9,305 \pm 0$, and $377 \pm 5^{\circ} \mathrm{C}$, while $50 \%$ of weight loss occurred at $451 \pm 3,454 \pm 1$, and $474 \pm 1^{\circ} \mathrm{C}$, respectively (Figure 1). Since the weight of the fabricated AD BPs was higher (approximately 30\%) than the theoretically predicted weight (i.e., $50 \mathrm{mg}$ ) because of the residual surfactants and only $10 \mathrm{mg}$ of BP was used for TGA, the data was rescaled considering the original weight of the BPs (Figure 2). The temperature where the weight of AD BPs became $50 \mathrm{mg}$ was recalculated considering the new scale and resulted in 381 and $362^{\circ} \mathrm{C}$ for acetone-cleaned and methanol-cleaned AD BPs, respectively. Both $\mathrm{AD}$ BPs showed a similar decomposition pattern as expected which led to the same conditions for the heat treatment.

The theoretically predicted weight of $50 \mathrm{mg}$ is the amount we calculated from the SWNT suspension for AD BPs and the amount we weighted on a scale for the powder form HiPco SWNTs, which may result in variations between BP samples since measuring the exact same amount every time is not possible. We assumed that samples below the theoretical weight 


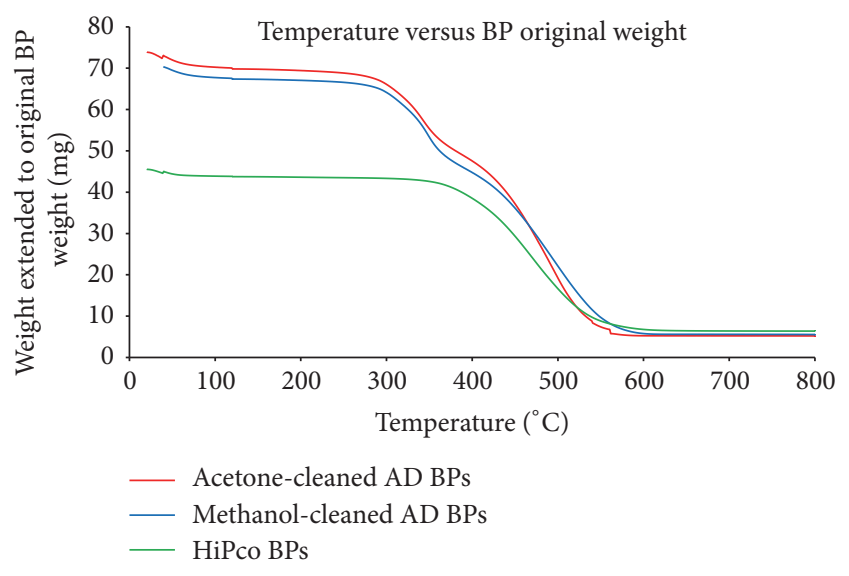

FIgUre 2: Rescaled TGA data.

will only contain the pure material and surfactants/solvents were all removed under the examined temperature and duration. In a study in which surfactants effect on the properties of multiwalled carbon nanotubes/polypropylene nanocomposites was examined, TGA showed that sodium dodecyl sulfate (SDS) powder started to decompose at around $200^{\circ} \mathrm{C}$ and more than $70 \%$ weight loss occurred at $300^{\circ} \mathrm{C}$ [11]. In another study aimed at removing the remnant surfactants and keeping intactness of the CVD SWNT films, sodium dodecylbenzenesulfonate (SDBS) powder started to decompose at $236^{\circ} \mathrm{C}$ and a heat treatment at $300^{\circ} \mathrm{C}$ for $5 \mathrm{hr}$ in air was selected [6]. The temperature (i.e., $300^{\circ} \mathrm{C}$ ) selected was between the oxidation temperature of SWNTs and the starting decomposition temperature of surfactants. Among examined surfactants, removal of SDBS showed the best performance in increasing transparency in CNT films, indicating that heat treatment successfully removed the surfactant. Studies on the removal of surfactants in transparent and conductive films (TCFs) made of CNTs have been more often reported for applications in electronic devices rather than sampling devices, including the previous study mentioned above. General approaches to remove surfactants to obtain more conductive TCFs include rinsing, heating, and acid treatment. AD SWNT film produced by a spray method in which the CNTs were suspended in SDS, sprayed on polyethylene terephthalate (PET) film, and rinsed in water several times was immersed in various acids and it was found that $\mathrm{HNO}_{3}$ could efficiently remove the remaining surfactant [5]. Photocatalysis using $\mathrm{ZnO}$ nanoparticles and Fenton reaction were tested to remove surfactants in CVD SWNT film fabricated by filtration method and the removal of residual surfactants was confirmed through Raman and X-ray photoelectron spectroscopy (XPS) spectra [7]. Few studies have examined TGA with BPs [12-14]. Sweetman et al. performed TGA with HiPco BPs fabricated through meso-tetra(4-sulfonatophenyl)porphyrin dihydrogen chloride (TSP) and phthalocyanine tetrasulfonic acid (TPS) suspension in air [12]. The mass of both samples remained relatively constant between 200 and $300^{\circ} \mathrm{C}$ and showed a sharp decrease between 400 and $600^{\circ} \mathrm{C}$ which is attributable to the decomposition of the dispersants and SWNTs. This behavior is showing a similar pattern to our study. Muramatsu et al.

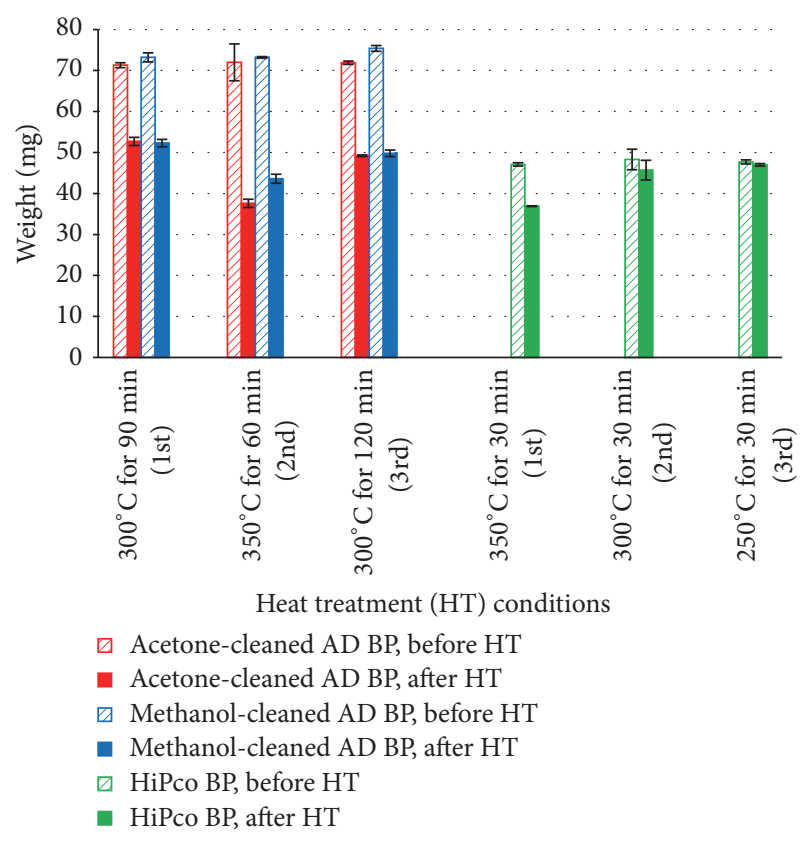

FIGURE 3: Weight change before and after heat treatment.

examined the oxygen stability of CVD double-walled carbon nanotube (DWNT) and SWNT BPs (type not specified) in an argon and oxygen (1\%) mixture [13]. DWNT-derived BP oxidized at a much higher temperature $\left(717^{\circ} \mathrm{C}\right)$ compared with SWNT-derived BP. The oxidation pattern of the SWNT $\mathrm{BP}$ was similar to that of our HiPco BPs.

3.2. Heat Treatment. Weight data and images showing the physical appearance of the BPs are shown in Figures 3 and 4 , respectively. Acetone-cleaned AD BPs lost approximately 26,48 , and $32 \%$ of their weight, whereas methanol-cleaned AD BPs decreased their weight by around 29,40 , and $34 \%$ at $300^{\circ} \mathrm{C}$ for $90 \mathrm{~min}, 350^{\circ} \mathrm{C}$ for $60 \mathrm{~min}$, and $300^{\circ} \mathrm{C}$ for $120 \mathrm{~min}$, respectively. HiPco BPs lost about 22,5 , and $1 \%$ at $350^{\circ} \mathrm{C}$ for $30 \mathrm{~min}, 300^{\circ} \mathrm{C}$ for $30 \mathrm{~min}$, and $250^{\circ} \mathrm{C}$ for $30 \mathrm{~min}$, respectively. However, when we recalculated the weight change from the theoretically predicted weight of $\mathrm{AD}$ BPs considering the surfactant effect, $+5,-25$, and $-2 \%$ weight of acetone-cleaned $\mathrm{AD} B P$ were changed after $\mathrm{HT}$ at the first $\left(300^{\circ} \mathrm{C}\right.$ for $\left.90 \mathrm{~min}\right)$, second $\left(350^{\circ} \mathrm{C}\right.$ for $\left.60 \mathrm{~min}\right)$, and third $\left(300^{\circ} \mathrm{C}\right.$ for $\left.120 \mathrm{~min}\right)$ conditions while there were $+5,-13$, and $0 \%$ changes in weight for methanol-cleaned $\mathrm{AD}$ BPs. As a result, at the first and third conditions, the weight change of AD BPs was minimal while for HiPco BPs weight change was minimal at the second and the third conditions.

Methanol-cleaned AD BPs either were swirled or become brittle even before heat treatment (Figure 4). Acetone-cleaned AD BPs also showed a similar pattern but only at the first condition, the samples kept the physical integrity. HiPco BPs did not manifest any change in physical integrity throughout the experiment and the samples were very flexible.

3.3. Characterization of Adsorption Properties. As shown in Table 1, acetone-cleaned AD BP had BET surface area with 
TABLE 1: Surface area (SA) and mean pore diameter $(d)$ after heat treatment.

\begin{tabular}{|c|c|c|c|c|c|c|c|}
\hline \multirow{2}{*}{ Conditions } & \multicolumn{2}{|c|}{ Acetone-cleaned AD BP } & \multicolumn{2}{|c|}{ Methanol-cleaned AD BP } & \multirow{2}{*}{ Conditions } & \multicolumn{2}{|c|}{ HiPco BP } \\
\hline & $\mathrm{SA}\left(\mathrm{m}^{2} / \mathrm{g}\right)$ & $d(\mathrm{~nm})$ & $\mathrm{SA}\left(\mathrm{m}^{2} / \mathrm{g}\right)$ & $d(\mathrm{~nm})$ & & $\mathrm{SA}\left(\mathrm{m}^{2} / \mathrm{g}\right)$ & $d(\mathrm{~nm})$ \\
\hline $\begin{array}{l}300^{\circ} \mathrm{C}, 90 \mathrm{~min} \\
\text { (1st) }\end{array}$ & $970 \pm 18$ & $5.9 \pm 0.0$ & $1074 \pm 10$ & $5.7 \pm 0.0$ & $\begin{array}{c}350^{\circ} \mathrm{C}, 30 \mathrm{~min} \\
\text { (1st) }\end{array}$ & $887 \pm 32$ & $6.6 \pm 0.1$ \\
\hline $\begin{array}{l}350^{\circ} \mathrm{C}, 60 \mathrm{~min} \\
(2 \mathrm{nd})\end{array}$ & $1228 \pm 13$ & $7.1 \pm 0.2$ & $1181 \pm 31$ & $6.6 \pm 0.2$ & $\begin{array}{c}300^{\circ} \mathrm{C}, 30 \mathrm{~min} \\
(2 \mathrm{nd})\end{array}$ & $933 \pm 54$ & $5.6 \pm 0.2$ \\
\hline $\begin{array}{l}300^{\circ} \mathrm{C}, 120 \mathrm{~min} \\
(3 \mathrm{rd})\end{array}$ & $1226 \pm 7$ & $5.8 \pm 0.2$ & $1227 \pm 33$ & $6.0 \pm 0.1$ & $\begin{array}{c}250^{\circ} \mathrm{C}, 30 \mathrm{~min} \\
(3 \mathrm{rd})\end{array}$ & $697 \pm 3$ & $6.2 \pm 0.1$ \\
\hline
\end{tabular}

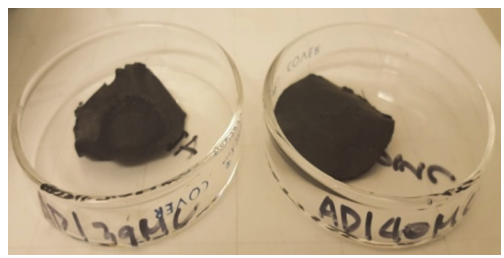

(a)

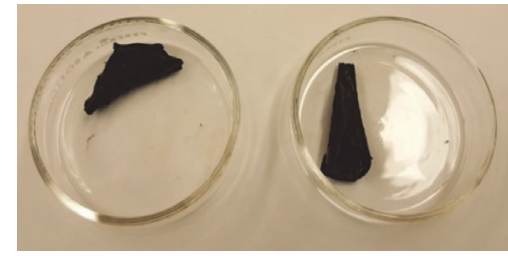

(b)

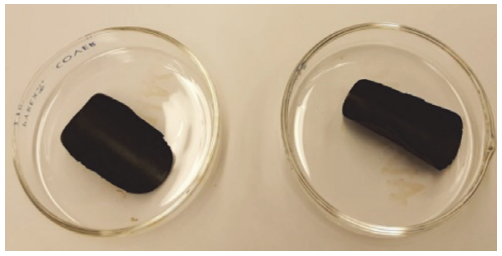

(c)

FIGURE 4: (a) Methanol-cleaned AD BPs before heat treatment and ((b) and (c)) acetone-cleaned AD BPs after heat treatment at $350^{\circ} \mathrm{C}$ for $60 \mathrm{~min}$ (2nd) and $300^{\circ} \mathrm{C}$ for $120 \mathrm{~min}$ (3rd), respectively.

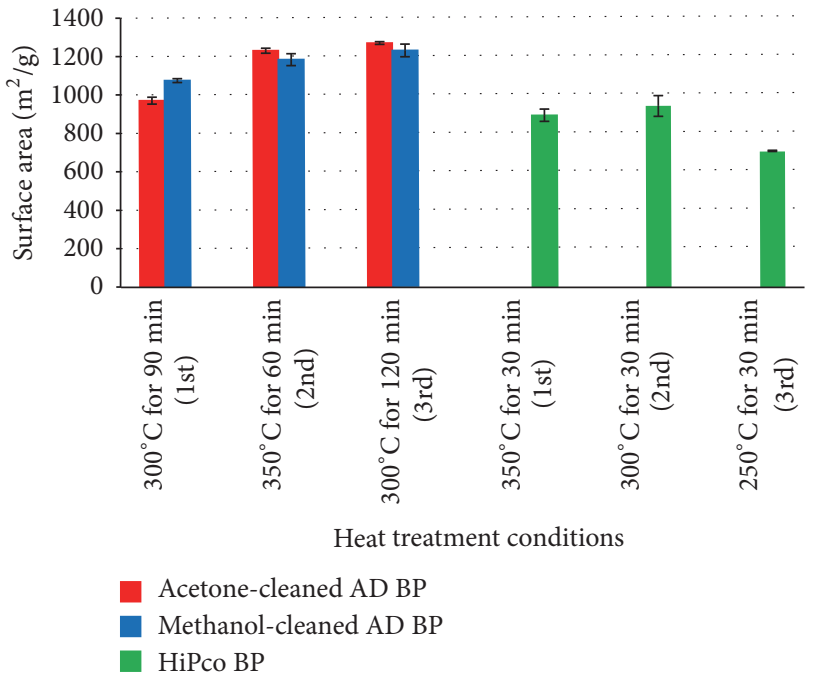

FIGURE 5: Surface areas comparison.

mean pore width of $970 \pm 18(5.9 \pm 0.0), 1228 \pm 13(7.1 \pm 0.2)$, and $1266 \pm 7(5.8 \pm 0.2) \mathrm{m}^{2} / \mathrm{g}$ while methanol-cleaned AD BP exhibited $1074 \pm 10(5.7 \pm 0.0), 1181 \pm 31$ (6.6 \pm 0.2$)$, and $1227 \pm 33(6.0 \pm 0.1) \mathrm{m}^{2} / \mathrm{g}$ at the first, second, and third heat treatment conditions, respectively (i.e., $300^{\circ} \mathrm{C}$ for $90 \mathrm{~min}$, $350^{\circ} \mathrm{C}$ for $60 \mathrm{~min}$, and $300^{\circ} \mathrm{C}$ for $\left.120 \mathrm{~min}\right)$. HiPco BP resulted in $887 \pm 32(6.6 \pm 0.1), 933 \pm 54(5.6 \pm 0.2)$, and $697 \pm 3(6.2 \pm$ $0.1) \mathrm{m}^{2} / \mathrm{g}$ at the first, second, and third conditions, respectively (i.e., $350^{\circ} \mathrm{C}$ for $30 \mathrm{~min}, 300^{\circ} \mathrm{C}$ for $30 \mathrm{~min}$, and $250^{\circ} \mathrm{C}$ for $30 \mathrm{~min}$ ). Figure 5 compares the BET surface areas between BPs at different heat treatment conditions. Overall, acetonecleaned and methanol-cleaned AD BPs revealed a similar pattern at all conditions as expected and all conditions yielded a high BET surface area of almost $1000 \mathrm{~m}^{2} / \mathrm{g}$ or more which is much higher (at least 2.5 times) than before the heat treatment, 322 and $387 \mathrm{~m}^{2} / \mathrm{g}$ for acetone-cleaned and methanolcleaned AD BPs, respectively [8]. At the second $\left(350^{\circ} \mathrm{C}\right.$ for $60 \mathrm{~min})$ and third $\left(300^{\circ} \mathrm{C}\right.$ for $\left.120 \mathrm{~min}\right)$ conditions, both $\mathrm{AD}$ BPs showed a relatively higher surface area than that at the first condition $\left(300^{\circ} \mathrm{C}\right.$ for $\left.90 \mathrm{~min}\right)$. For HiPco BPs, the first $\left(350^{\circ} \mathrm{C}\right.$ for $\left.30 \mathrm{~min}\right)$ and second $\left(300^{\circ} \mathrm{C}\right.$ for $\left.30 \mathrm{~min}\right)$ conditions resulted in a relatively higher surface area while the surface area at the third condition $\left(250^{\circ} \mathrm{C}\right.$ for $\left.30 \mathrm{~min}\right)$ was not much changed compared to before treatment, $649 \mathrm{~m}^{2} / \mathrm{g}$ [8].

Since methanol-cleaned AD BPs did not keep their physical integrity during the experiment, only acetone-cleaned $\mathrm{AD}$ BPs were considered to be chosen for our next study in which BPs treated with the selected heat treatment conditions will be examined for desorption efficiency through photothermal desorption (PTD). Although the surface area of the acetonecleaned AD BPs was relatively lower at the first condition $\left(300^{\circ} \mathrm{C}\right.$ for $\left.90 \mathrm{~min}\right)$, the condition was selected since the samples were physically intact only at that condition and weight change was minimal. On the other hand, the second condition $\left(300^{\circ} \mathrm{C}\right.$ for $\left.30 \mathrm{~min}\right)$ was selected for HiPco BPs because of the minimal loss in weight and relatively high surface area.

Many studies on the purification of CNT powder through chemical, physical, or a combination of both processes are focused on the removal of metal catalysts and carbonaceous impurities in CNTs [15] and as far as we know this study is the first investigation of the heat treatment effect on BPs to improve the adsorption properties by mainly removing surfactant residues and any impurities involved in the process. From our previous study, it was suggested that surfactants were not completely removed even after cleaning during the fabrication process. Most purification studies employ a combined process of acid treatment (i.e., liquid-phase oxidation) followed by gas-phase oxidation under heat [15-19]. HiPco SWNTs $\left(528 \mathrm{~m}^{2} / \mathrm{g}\right)$ were purified with acids and heat 
treatment was selectively performed [16]. Among four acids examined ( $\mathrm{HCl}, \mathrm{HF}, \mathrm{H}_{2} \mathrm{SO}_{4}$, and $\mathrm{HNO}_{3}$ ), HF treated SWNTs for $4-8 \mathrm{hr}$ yielded $635 \mathrm{~m}^{2} / \mathrm{g}$ while HF treatment followed by $600^{\circ} \mathrm{C}$ heat treatment for 6 hours in inert atmosphere showed the highest increase in surface area $\left(1555 \mathrm{~m}^{2} / \mathrm{g}\right)$. However, further heat treatment at $1000^{\circ} \mathrm{C}$ for 6 hours diminished it to $806 \mathrm{~m}^{2} / \mathrm{g}$, eliminating porous structure. In another study, after the heat treatment of SWNTs (not specified, $298 \mathrm{~m}^{2} / \mathrm{g}$ ) at $800^{\circ} \mathrm{C}$ for 2 hours in $\mathrm{CO}_{2}$ and $\mathrm{H}_{2}$ environments, surface area was increased to 249 and $351 \mathrm{~m}^{2} / \mathrm{g}$, respectively. 52 and $30 \%$ of weight loss occurred in $\mathrm{CO}_{2}$ and $\mathrm{H}_{2}$ environments, respectively, while keeping the original pore size distribution of the SWNTs [17]. On the other hand, nitric acid treatment at $70^{\circ} \mathrm{C}$ for 5 hours changed it completely, resulting in surface area of $544 \mathrm{~m}^{2} / \mathrm{g}$.

Heat treatment in air could have oxidized our samples which possibly changed the chemical property or functionalized the materials but we believe that oxidation was minimal in our study since it was performed in a small sized furnace with only a small vent in which air circulates naturally and in a temperature below which the oxidation of SWNTs powder starts $\left(380-400^{\circ} \mathrm{C}\right)[6,9,10]$. A detailed chemical analysis was not performed in this study to determine if all impurities are completely eliminated through the heat treatment; rather, we used a gravimetric method, which did not give us accurate information on the effect of heat treatment in terms of chemical composition. Since the scope of this study was to find a simple way to remove impurities involved in the fabrication process of BP in order to improve adsorption property, surface area analysis was the focus rather than elemental analysis.

\section{Conclusions}

The effect of heat treatment on the adsorption property was examined on the fabricated AD BP and HiPco BP. Considering the BET surface area data and changes in weight and physical integrity before and after heat treatment, conditions at $300^{\circ} \mathrm{C}$ for $90 \mathrm{~min}$ and $300^{\circ} \mathrm{C}$ for $30 \mathrm{~min}$ were determined to be the most appropriate for acetone-cleaned $\mathrm{AD} B P$ and HiPco BP, respectively. With those selected conditions, further investigations on photothermal desorption (PTD) will be followed.

\section{Disclosure}

Any opinions, findings, and conclusions or recommendations expressed in this material are those of the authors and do not necessarily reflect the views of National Institute for Occupational Safety and Health (NIOSH) or represent an endorsement by NIOSH.

\section{Competing Interests}

The authors declare that they have no competing interests.

\section{Acknowledgments}

The research presented in this manuscript was partially supported by NIOSH through an R21 grant (1 R21 OH010373).

\section{References}

[1] Z. Shi, X. Chen, X. Wang, T. Zhang, and J. Jin, "Fabrication of superstrong ultrathin free-standing single-walled carbon nanotube films via a wet process," Advanced Functional Materials, vol. 21, no. 22, pp. 4358-4363, 2011.

[2] J. Di, D. Hu, H. Chen et al., "Ultrastrong, foldable, and highly conductive carbon nanotube film," ACS Nano, vol. 6, no. 6, pp. 5457-5464, 2012.

[3] Z. Wu, Z. Chen, X. Du et al., "Transparent, conductive carbon nanotube films," Science, vol. 305, no. 5688, pp. 1273-1276, 2004.

[4] M. Kaempgen, G. S. Duesberg, and S. Roth, "Transparent carbon nanotube coatings," Applied Surface Science, vol. 252, no. 2, pp. 425-429, 2005.

[5] H.-Z. Geng, K. K. Ki, P. S. Kang, S. L. Young, Y. Chang, and H. L. Young, "Effect of acid treatment on carbon nanotube-based flexible transparent conducting films," Journal of the American Chemical Society, vol. 129, no. 25, pp. 7758-7759, 2007.

[6] J. Wang, J. Sun, L. Gao et al., "Improving the conductivity of single-walled carbon nanotubes films by heat treatment," Journal of Alloys and Compounds, vol. 485, no. 1-2, pp. 456-461, 2009.

[7] J. Wang, J. Sun, L. Gao et al., "Removal of the residual surfactants in transparent and conductive single-walled carbon nanotube films," The Journal of Physical Chemistry C, vol. 113, no. 41, pp. 17685-17690, 2009.

[8] J. Oh, E. L. Floyd, T. C. Watson, and C. T. Lungu, "Fabrication and adsorption characterization of single-walled carbon nanotube (SWNT) buckypaper (BP) for use in air samplers," Analytical Methods, vol. 8, no. 21, pp. 4197-4203, 2016.

[9] Y. Liu, L. Gao, J. Sun et al., "A multi-step strategy for cutting and purification of single-walled carbon nanotubes," Carbon, vol. 45, no. 10, pp. 1972-1978, 2007.

[10] S. Gajewski, H.-E. Maneck, U. Knoll et al., "Purification of single walled carbon nanotubes by thermal gas phase oxidation," Diamond and Related Materials, vol. 12, no. 3-7, pp. 816-820, 2003.

[11] H. K. F. Cheng, Y. Pan, N. G. Sahoo et al., "Improvement in properties of multiwalled carbon nanotube/polypropylene nanocomposites through homogeneous dispersion with the aid of surfactants," Journal of Applied Polymer Science, vol. 124, no. 2, pp. 1117-1127, 2012.

[12] L. J. Sweetman, L. Nghiem, I. Chironi, G. Triani, M. In Het Panhuis, and S. F. Ralph, "Synthesis, properties and water permeability of SWNT buckypapers," Journal of Materials Chemistry, vol. 22, no. 27, pp. 13800-13810, 2012.

[13] H. Muramatsu, T. Hayashi, Y. A. Kim et al., "Pore structure and oxidation stability of double-walled carbon nanotube-derived bucky paper," Chemical Physics Letters, vol. 414, no. 4-6, pp. 444-448, 2005.

[14] T. V. Sreekumar, T. Liu, S. Kumar, L. M. Ericson, R. H. Hauge, and R. E. Smalley, "Single-wall carbon nanotube films," Chemistry of Materials, vol. 15, no. 1, pp. 175-178, 2003.

[15] P.-X. Hou, C. Liu, and H.-M. Cheng, "Purification of carbon nanotubes," Carbon, vol. 46, no. 15, pp. 2003-2025, 2008. 
[16] L. Lafi, D. Cossement, and R. Chahine, "Raman spectroscopy and nitrogen vapour adsorption for the study of structural changes during purification of single-wall carbon nanotubes," Carbon, vol. 43, no. 7, pp. 1347-1357, 2005.

[17] Y. H. Hu and E. Ruckenstein, "Pore size distribution of singlewalled carbon nanotubes," Industrial and Engineering Chemistry Research, vol. 43, no. 3, pp. 708-711, 2004.

[18] C.-M. Yang, K. Kaneko, M. Yudasaka, and S. Iijima, "Effect of purification on pore structure of HiPco single-walled carbon nanotube aggregates," Nano Letters, vol. 2, no. 4, pp. 385-388, 2002.

[19] I. W. Chiang, B. E. Brinson, A. Y. Huang et al., "Purification and characterization of single-wall carbon nanotubes (SWNTs) obtained from the gas-phase decomposition of CO (HiPco process)," The Journal of Physical Chemistry B, vol. 105, no. 35, pp. 8297-8301, 2001. 

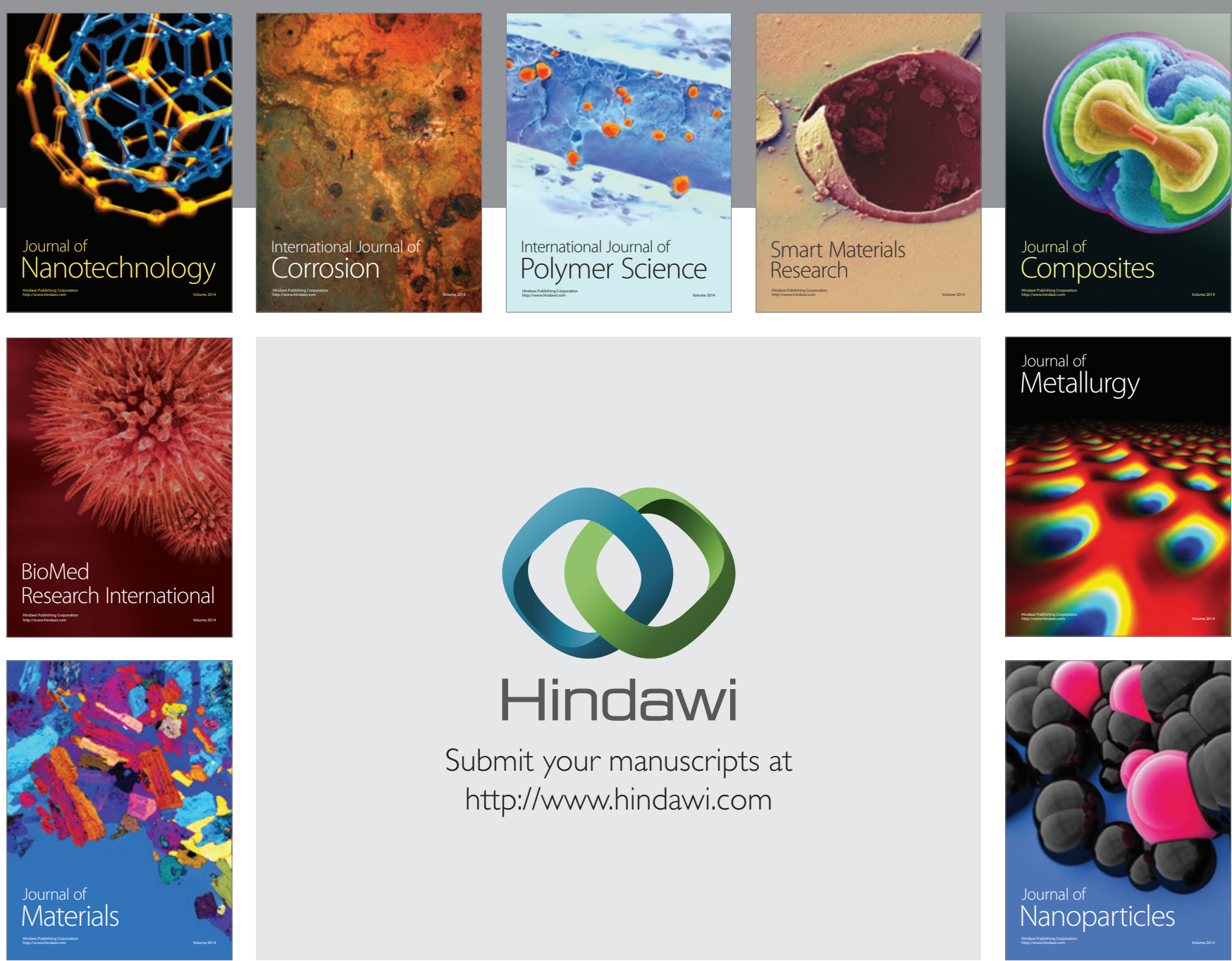

\section{Hindawi}

Submit your manuscripts at

http://www.hindawi.com

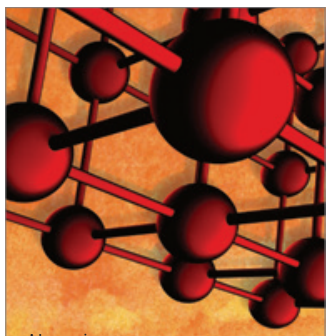

Materials Science and Engineering
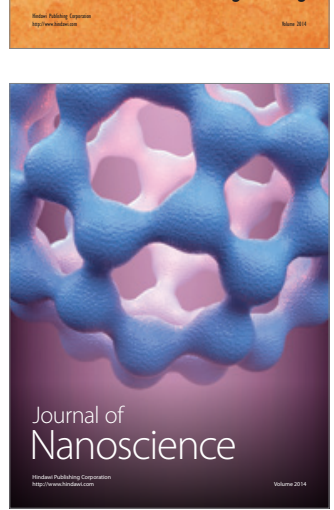
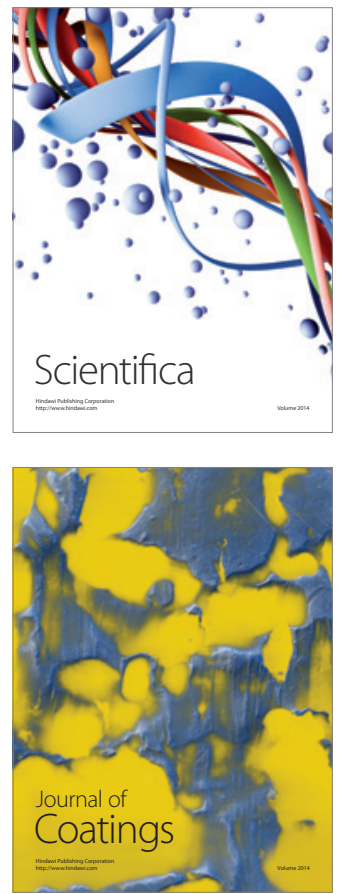
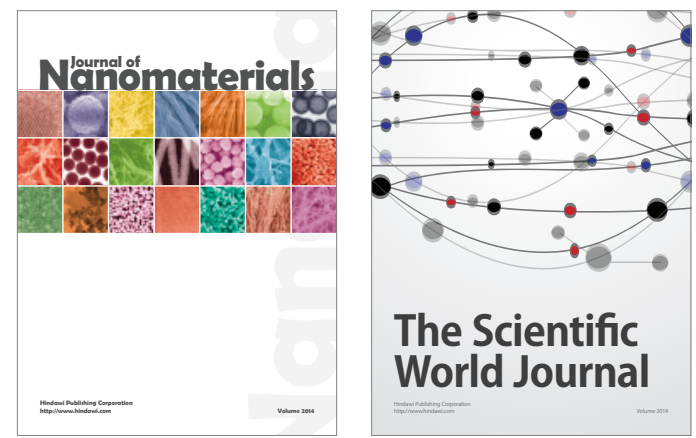

The Scientific World Journal
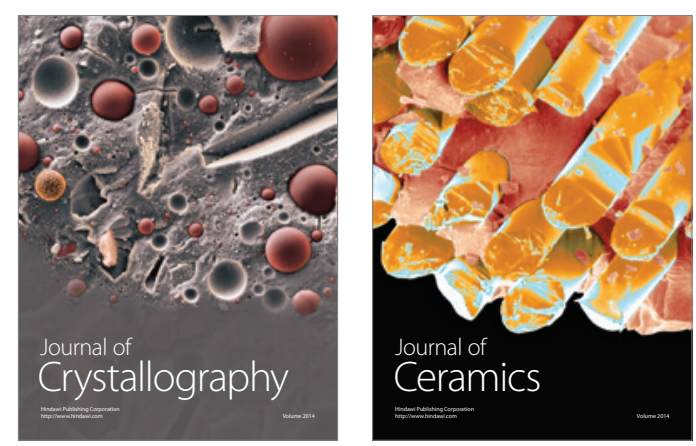
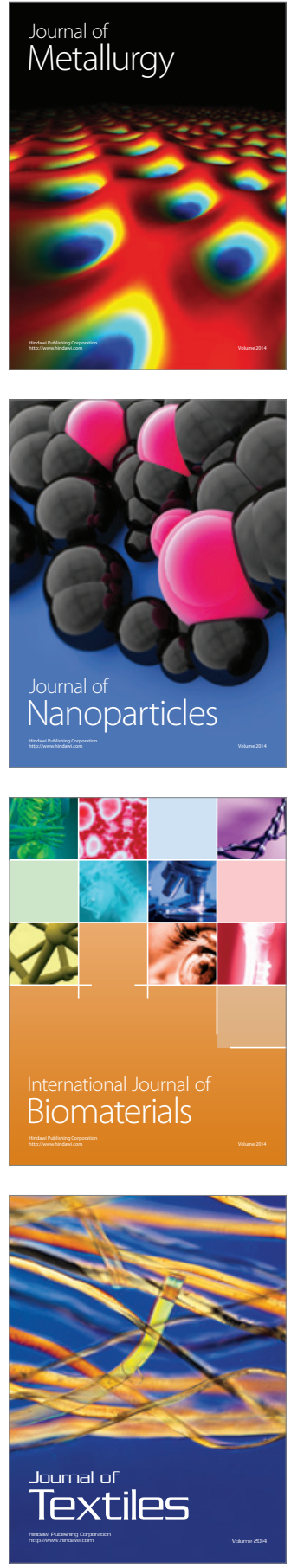